\title{
On Constituents of the Periodic Layered Microstructure Developed in the Solid-State Reaction Between Zinc and $\mathrm{Co}_{2} \mathrm{Si}$
}

\author{
J. WOJEWODA-BUDKA, A. WIERZBICKA-MIERNIK, \\ L. LITYNSKA-DOBRZYNSKA, A. KORNEVA, and A. KODENTSOV
}

\begin{abstract}
The composition and crystal structure of the constituents of the periodic layered microstructure developed during the solid-state reaction between $\mathrm{Co}_{2} \mathrm{Si}$ intermetallic and zinc at $390{ }^{\circ} \mathrm{C}$ were investigated using scanning electron microscopy, transmission electron microscopy, and electron-probe microanalysis. It was demonstrated that the periodic layered morphology generated in the reaction zone of the $\mathrm{CO}_{2} \mathrm{Si} / \mathrm{Zn}$ diffusion couples consists of bands of in situ-formed precipitates of cubic CoSi intermetallic, embedded in a continuous matrix of $\mathrm{Co}-\mathrm{Zn}$-based hexagonal phase containing a small amount of silicon. It was suggested that the formation of the hexagonal intermetallic of the same crystal structure as the binary $\delta$ phase of the Co-Zn system can be attributed to the possible stabilizing effect of silicon: the $\delta$-phase structure becomes stable in the ternary Co-Si-Zn system at $390{ }^{\circ} \mathrm{C}$.
\end{abstract}

https://doi.org/10.1007/s11661-020-05788-z

(c) The Author(s) 2020

\section{INTRODUCTION}

THE present study originates in the quest for better understanding of the operational mechanism governing periodic layer formation in displacement solid-state reactions. This special class of reaction zone morphology, which has been found in several metal/ceramic (i.e., $\mathrm{SiC} / \mathrm{Ni}, \mathrm{SiC} / \mathrm{Pt}$, and $\mathrm{SiO}_{2} / \mathrm{Mg}$ ) as well as in a number of metallic (e.g., $\mathrm{Fe}_{3} \mathrm{Si} / \mathrm{Zn}, \mathrm{Co}_{2} \mathrm{Si} / \mathrm{Zn}, \mathrm{Ni}_{3} \mathrm{Si}_{2} / \mathrm{Zn}$, and $\mathrm{Ni}_{50} \mathrm{Co}_{20} \mathrm{Fe}_{30} / \mathrm{Mg}$ ) systems, is now understood as a manifestation of the Kirkendall effect accompanying reactive phase formation in the solid state. The latter induces a shift of in-situ inert inclusions (reaction product) toward the faster diffusing component. In a more general way, the mechanism is operative when the components have widely different mobilities in adjacent reaction product layers.

More details concerning this peculiar reaction phenomenon can be found in our recent compilation, ${ }^{[1]}$ and here, we will concentrate only on the diffusion microstructure developed in the $\mathrm{Co}_{2} \mathrm{Si} / \mathrm{Zn}$ system. The selection of this system was dictated by three reasons: (1)

J. WOJEWODA-BUDKA, A. WIERZBICKA-MIERNIK, L. LITYNSKA-DOBRZYNSKA, and A. KORNEVA are with the Institute of Metallurgy and Materials Science, Polish Academy of Sciences, 25 Reymonta St., 30-059 Kraków, Poland. Contact email: j.wojewoda@imim.pl A. KODENTSOV is with Mat-Tech BV, Development \& Testing, Ekkersrijt 4605, 5692 DR Son, The Netherlands.

Manuscript submitted November 20, 2019.

Article published online May 1, 2020 this is the finest periodic layered structure (with spacing of $\sim 1 \mu \mathrm{m}$ ) found until now in metal silicide systems, ${ }^{[2,3]}$ (2) the apparent influence of crystallographic orientation of the $\mathrm{CO}_{2} \mathrm{Si}$-substrate grains on the band frequency (spacing) within the product periodic morphology (Figure 1(a)), and (3) the striking pattern (appearance of "loops" composed of CoSi particles, resembling the dislocation loops emerging from a Bardeen-Herring source ${ }^{[4]}$ ) observed in a section of the periodic layered reaction zone of the $\mathrm{Co}_{2} \mathrm{Si} / \mathrm{Zn}$ couple perpendicular to the diffusion direction (Figure 1(b)). This peculiar pattern is also reminiscent of the spiral wave activity in the thin-layer homogeneous Belousov-Zhabotincky reaction. ${ }^{[5]}$ (Note: Before embarking upon the present investigation (for the sake of comparison), we have reproduced (repeated) some diffusion couple experiments reported in Reference 2).

The purpose of this communication is twofold:

(1) to present structural information about constituents of the product layered morphology developed in the annealed $\mathrm{Co}_{2} \mathrm{Si} / \mathrm{Zn}$ diffusion couples; and

(2) to draw attention to some apparent ambiguities in correlating available data on binary Co-Zn intermetallics and crystallographic information obtained from the examination of the diffusion zone in the $\mathrm{Co}_{2} \mathrm{Si} / \mathrm{Zn}$ reaction couples. 
a

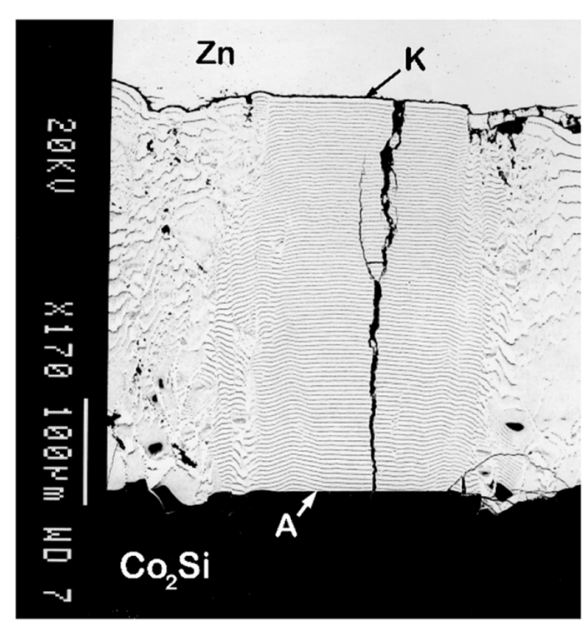

b

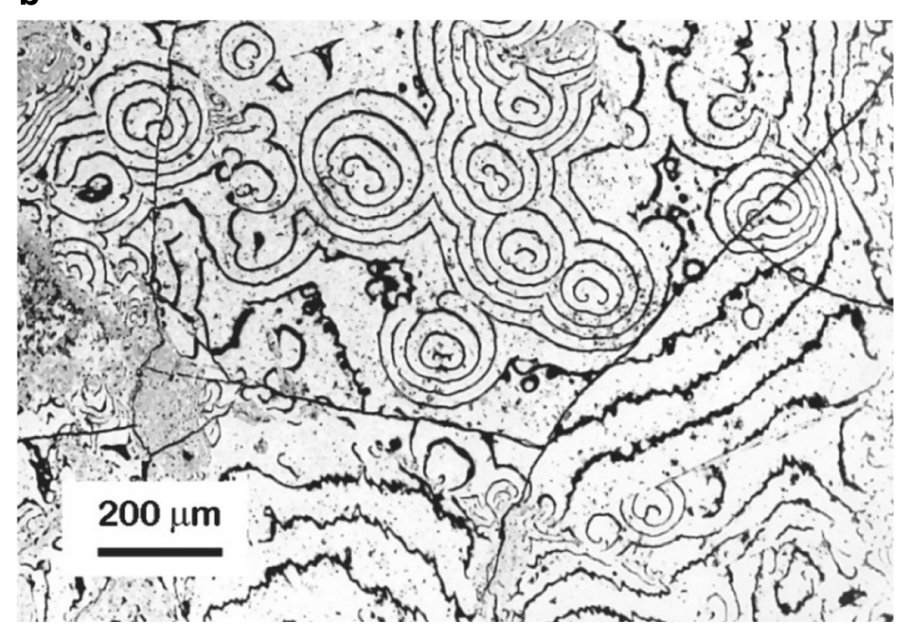

Fig. 1-BEIs of the reaction zone morphology developed in the $\mathrm{Co}_{2} \mathrm{Si} / \mathrm{Zn}$ diffusion couple annealed at $390{ }^{\circ} \mathrm{C}$ for $28 \mathrm{~h}$ in argon showing $(a)$ the general view (at point $\mathbf{A}$, the substrate grain boundary meets the reaction product layer) and $(b)$ the cross section of the reaction zone of the annealed $\mathrm{Co}_{2} \mathrm{Si} / \mathrm{Zn}$ couple perpendicular to the diffusion direction: the Co-Zn matrix phase exhibits white contrast in the BEIs, and the CoSi intermetallic exhibits dark contrast. (The letter $\mathrm{K}$ in (a) indicates the location of the Kirkendall plane.) Note the unfortunate artifact (crack running perpendicular to the reaction product $/ \mathrm{Co}_{2} \mathrm{Si}$ interface) that stems from the metallographic preparation of the cross-sectional sample.

\section{EXPERIMENTAL}

Precisely weighed amounts of cobalt (of 99.95 pct purity, Alfa Aesar) and silicon (of 99.999 pct purity, Alfa Aesar) were melted in an induction furnace under argon atmosphere to obtain homogenous $\mathrm{Co}_{2} \mathrm{Si}$ intermetallic. The $\mathrm{Co}_{2} \mathrm{Si}$ rods were made using an arc furnace equipped with an attachment for the suction casting. In this casting technique, a premixed alloy is arc melted and the product melt is subsequently sucked into a copper mold due to the pressure difference prevailing in the chamber $(\sim 800$ mbar $)$ and in the vacuum $\left(\sim 2 \times 10^{-2}\right.$ mbar) container ("receiver"). After electric arc ignition, the melting current was gradually increased from 80 to approximately $230 \mathrm{~A}$. The melt was heated for $\sim 5$ seconds, and after that, it was sucked into the mold by opening a valve separating the furnace chamber and the receiver.

Solid-state reactions between $\mathrm{Co}_{2} \mathrm{Si}$ and zinc (of 99.994 pct purity, Alfa Aesar) were conducted in a chamber furnace in quartz ampules at $390{ }^{\circ} \mathrm{C}$ for 144 hours. In all experiments, the temperature was controlled within \pm 2 deg. However, the actual temperature at the place of the sample might deviate $\pm 5 \mathrm{deg}$ from the value reported here.

After annealing and standard metallographic preparation, cross sections of the annealed diffusion couples were first analyzed by scanning electron microscopy (SEM, Quanta 3D, FEI) and electron-probe microanalysis (EPMA). The EPMA was performed at an accelerating voltage of $20 \mathrm{kV}$ using pure $\mathrm{Co}, \mathrm{Si}$, and $\mathrm{Zn}$ as standards.

Further examination of the reaction products formed in the diffusion zones was carried out with transmission electron microscopy (TEM, Tecnai G2, FEI). Cross-sectional TEM specimens were prepared using dual beam technology SEM-focused ion beam (FIB). In this case, a so-called "lift-out" technique was used. An FIB (Quanta
2D, FEI) instrument, which allowed probing specimens from well-defined positions within the reaction zone, located closely either to a $\mathrm{Co}_{2} \mathrm{Si}$ or $\mathrm{Zn}$ end-member of the $\mathrm{Co}_{2} \mathrm{Si} / \mathrm{Zn}$ diffusion couple was employed.

\section{RESULTS AND DISCUSSION}

In Figure 2, a series of backscattered electron images (BEIs) of the reaction zone in the $\mathrm{Co}_{2} \mathrm{Si} / \mathrm{Zn}$ diffusion couple annealed at $390{ }^{\circ} \mathrm{C}$ for 144 hours is presented. The periodic layered morphology found in these experiments is very much similar to that observed in the previous studies. ${ }^{[1-3,6-8]}$ The reaction product consists of a continuous main layer and thin bands of particles, exhibiting "dark" contrast in BEIs, embedded in the matrix phase. Some particles can also be seen in between the bands. The microstructure of the reaction zone is formed by cells with remarkably distinct morphologies. Some are regular and consist of parallel alternating layers, while some are irregular, but a certain kind of periodicity can still be observed. From the analysis of the intensity distribution of characteristic X-ray radiation across the product layer, it appears that bands within the periodic morphology contain silicon and cobalt (Figure 2(d)).

Electron-microprobe measurements show that the Co content in the matrix phase of the reaction zone varies from 11.4 to 12.1 at. pet at the $\mathrm{Co}_{2} \mathrm{Si}$ side to 7.7 to 9.5 at. pct at the $\mathrm{Zn}$ side of the transition zone, which corresponds, respectively, to $\gamma_{1}$ and $\gamma_{2}$ intermediate phases present in the binary Co-Zn system (Figure 3). ${ }^{[9]}$ In addition, a small amount of silicon (up to 0.7 at. pct) has also been detected in the matrix layer.

The solid-state domain of the ternary Co-Zn-Si system has not been extensively investigated, but a cross section at $395{ }^{\circ} \mathrm{C}$ was tentatively described by Osinski. ${ }^{[6]}$ No ternary compounds exist on this isotherm. It was 

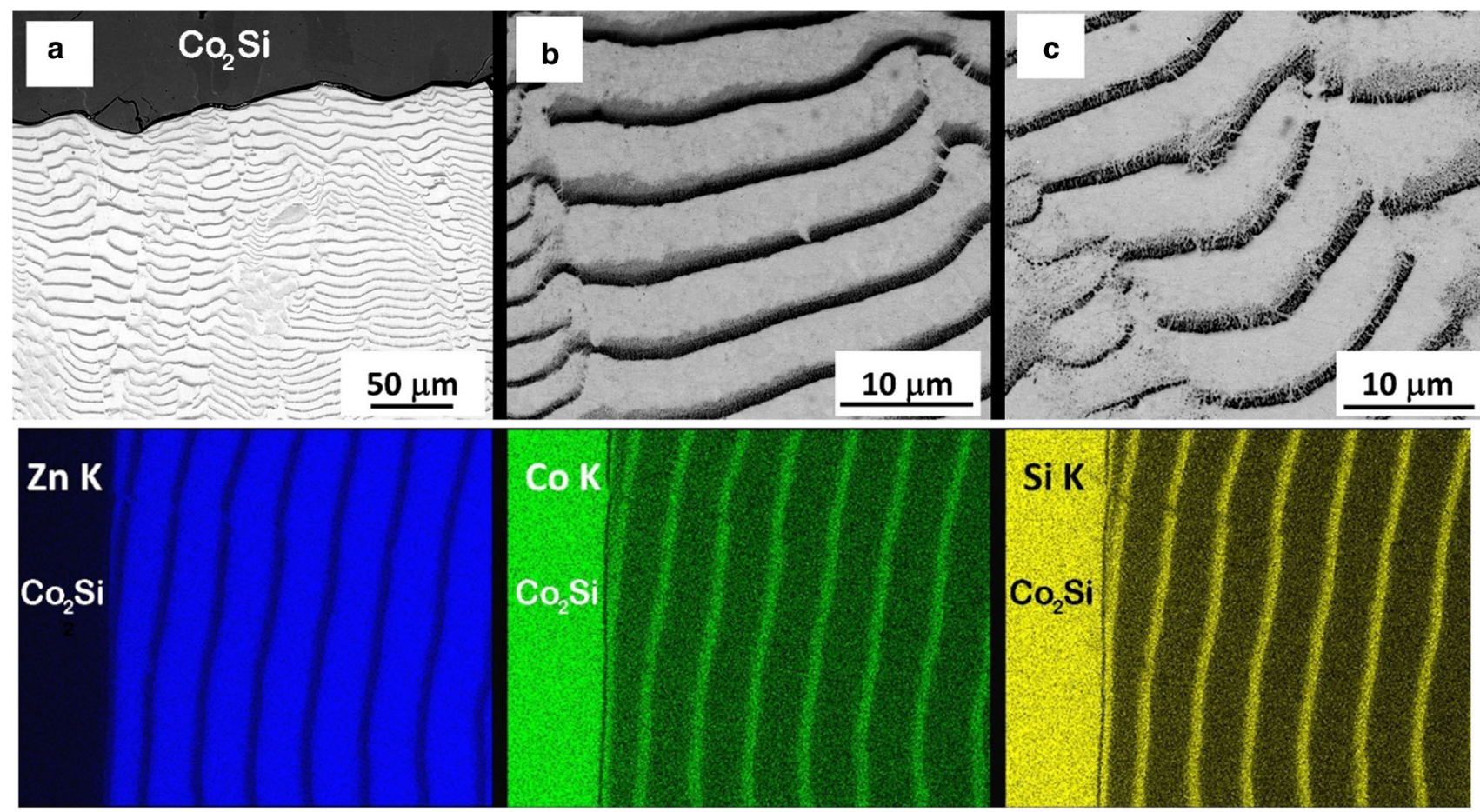

d

Fig. 2-BEIs of the transition zone morphology developed in the $\mathrm{Co}_{2} \mathrm{Si} / \mathrm{Zn}$ diffusion couple annealed at $390{ }^{\circ} \mathrm{C}$ for $144 \mathrm{~h}$ : $(a)$ general view of the diffusion zone close to the $\mathrm{Co}_{2} \mathrm{Si}$ end-member; and $(b)$ and $(c)$ variations of the periodic layered morphology of the reaction product, revealing a two-phase nature of the bands within the microstructure: the Co-Zn matrix phase exhibits white contrast in the BEIs, and the CoSi intermetallic exhibits dark contrast, together with the intensity distribution of the characteristic X-ray radiation $(d)$ of $\mathrm{Zn} K_{\alpha}$, Co $K_{\alpha}$, and $\mathrm{Si} K_{\alpha}$ across the reaction product layer.

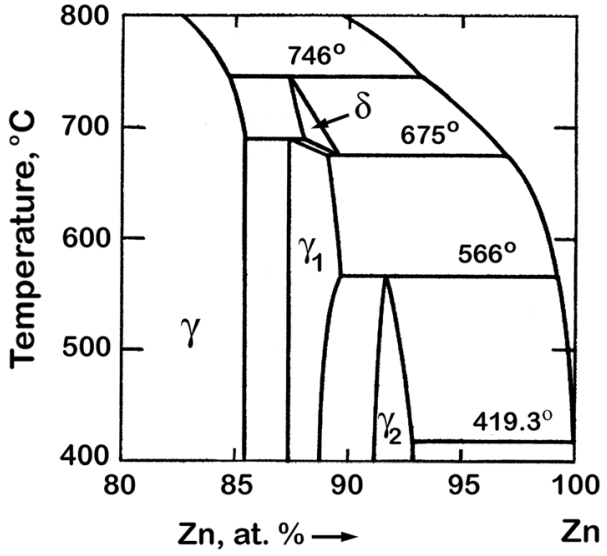

Fig. 3-Zinc-rich part of the binary Co- $\mathrm{Zn}$ phase diagram.

found that binary Co-Zn phases, $\gamma_{1}$ and $\gamma_{2}$, are in equilibrium with the CoSi intermetallic, and the terminal solubility of silicon in these Co-Zn binary phases as well as that of zinc in the CoSi is very low (below 1 at. pet).

Later, Wang et al..$^{[10]}$ conducted an experimental study and thermodynamic calculations of this ternary system but at higher temperatures, viz. $450{ }^{\circ} \mathrm{C}$ to $1050{ }^{\circ} \mathrm{C}$. No ternary phases were found by these authors. Also, phase relations involving binary $\mathrm{Co}-\mathrm{Zn}$ phases, $\gamma_{1}$ and $\gamma_{2}$, and the CoSi as well as the terminal solid-state solubilities in the binary compounds were reported to be similar to those determined in Reference 6.

As to the interaction in ternary $\mathrm{Co}_{2} \mathrm{Si} / \mathrm{Zn}$ diffusion couples, the only publication found in the literature (apart from the already mentioned work of van Loo and co-workers ${ }^{[2,7,8]}$ and by Yongchong et al ${ }^{[3]}$ ) is that by Liu et al. ${ }^{[11]}$ However, it is important to realize that, in the cited article, the reaction phenomena in the $\mathrm{Co}_{2} \mathrm{Si} /$ $\mathrm{Zn}$ system have been studied at $450{ }^{\circ} \mathrm{C}$, i.e., above the melting point of $\mathrm{Zn}$, and therefore, a direct comparison of these results with the diffusion couple experiments performed in the present investigation is rather difficult. Although a certain kind of "periodicity" in the arrangement of the phases inside the reaction zone of the "solid-liquid" diffusion couples has been observed, the product microstructure formed under these conditions does not lend itself to a straightforward analysis. The presence of "unreacted" zinc within the product layer renders the rationalization of the morphological developments in the reaction zone very cumbersome.

It is also interesting to mention here the results on the reactive phase formation in binary $\mathrm{Co} / \mathrm{Zn}$ diffusion couples available in the literature. Duchenko et al. ${ }^{[12,13]}$ investigated the reaction kinetics in $\mathrm{Co} / \mathrm{Zn}$ "solid-solid" diffusion couples over the temperature range $250{ }^{\circ} \mathrm{C}$ to $400{ }^{\circ} \mathrm{C}$, but the preparation of the initial couples was accomplished by dipping of Co pieces into molten zinc. The authors reported that, during annealing at $250{ }^{\circ} \mathrm{C}$ to $400{ }^{\circ} \mathrm{C}$, two product layers grow between cobalt and 


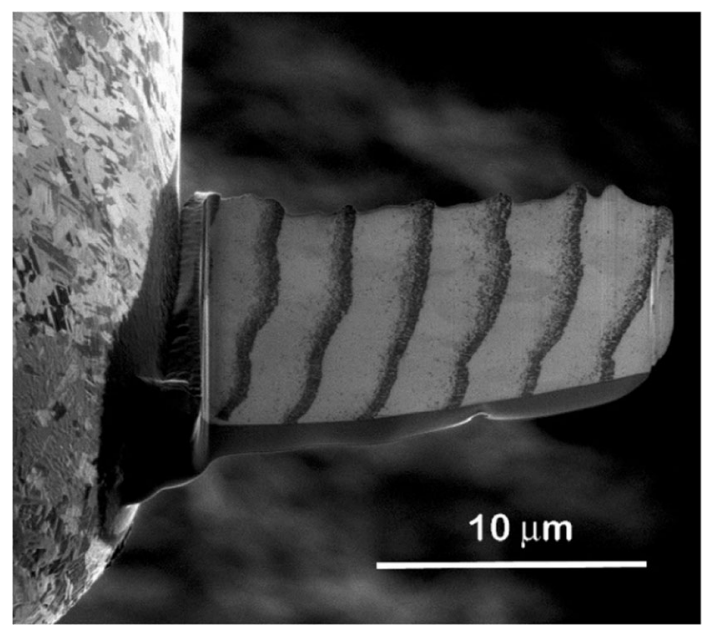

Fig. 4-TEM specimen (lamella) taken from the reaction zone of the annealed $\left(390{ }^{\circ} \mathrm{C} ; 144 \mathrm{~h}\right) \mathrm{Co}_{2} \mathrm{Si} / \mathrm{Zn}$ diffusion couple. The periodic microstructure of the lamella is clearly visible. (The secondary electron image was generated by FIB.) zinc. The layer next to the zinc end-member was found to be the $\gamma_{2}$ phase of the Co-Zn binary system, whereas the nature of the second layer formed in the diffusion zone was not unequivocally established. In contrast, Takamatsu et al., ${ }^{[14]}$ in their study on reaction kinetics in "sandwich" $\mathrm{Zn} / \mathrm{Co} / \mathrm{Zn}$ (solid-solid) couples, demonstrated that, even at relatively low temperatures, $250{ }^{\circ} \mathrm{C}$ to $300{ }^{\circ} \mathrm{C}$, three product layers, i.e., of $\gamma, \gamma_{1}$, and $\gamma_{2}$ phases of the Co-Zn system, can be identified inside the diffusion zone.

Further investigation of the reaction zone was carried out with TEM on the FIB fabricated specimens. A typical example of the TEM specimen examined is shown in Figure 4. Close inspection of the reaction zone in the vicinity of the $\mathrm{Co}_{2} \mathrm{Si}$ substrate, where the composition of the $\mathrm{Co}-\mathrm{Zn}$ reaction product corresponds to the $\gamma_{1}$ phase, revealed that the bands are actually agglomerates of small particles embedded in the intermetallic matrix (Figures 5(a) and (b)). Electron diffraction confirmed the expected presence of the cubic CoSi as inclusions within the bands of the periodic microstructure (Figure 5(c)).
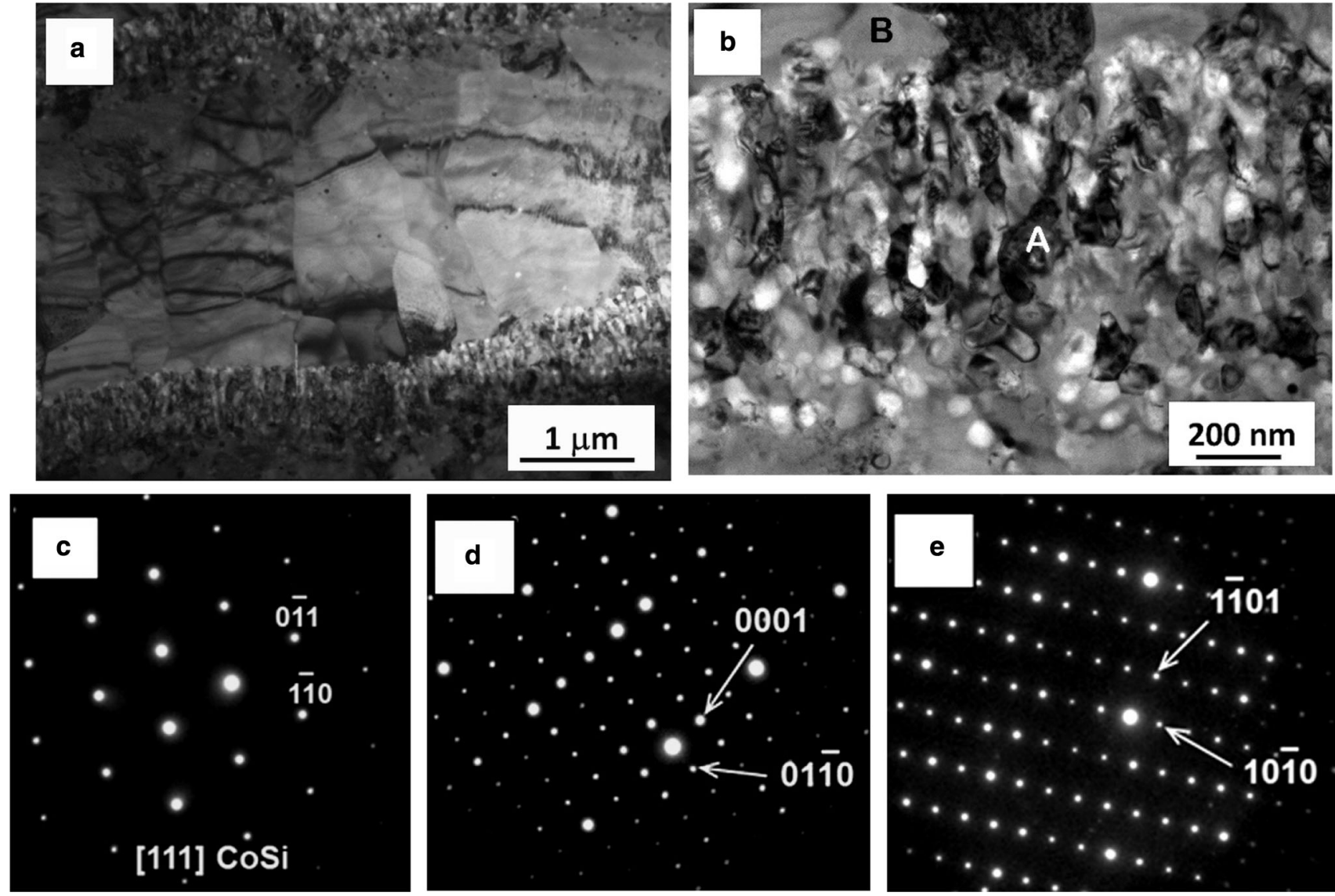

Fig. 5- BF TEM images of the reaction zone at the location close to the $\mathrm{Co}_{2} \mathrm{Si}$ end-member of the annealed $\left(390{ }^{\circ} \mathrm{C}, 144 \mathrm{~h}\right) \mathrm{Co} 2 \mathrm{Si} / \mathrm{Zn}$ diffusion couple: $(a)$ general view and $(b)$ magnified area showing fine structure of the two-phase band along with SAEDs taken from $(c)$ the inclusion constituting band within the periodic microstructure (indicated by $\mathbf{A}$ in the BF image in (b)) and indexed as [111] direction in the cubic lattice of $\mathrm{CoSi}\left(\mathrm{B} 20 ; c P 8 ; P 2{ }_{1} 3 ; a=0.4447 \mathrm{~nm}^{[15]}\right)$ and $(d)$ and $(e)$ obtained from the matrix phase (indicated by $\mathbf{B}$ in the BF image in (b)) and indexed as $[2 \overline{1} \overline{1} 0]$ and $[1 \overline{2} 1 \overline{3}]$ directions in the hexagonal lattice with the data for binary compound $\delta-\mathrm{Co}_{2} \mathrm{Zn}_{15}\left(P 6_{2}, a=1.1292 \mathrm{~nm}\right.$, and $c=0.7750$ $\left.\mathrm{nm}^{[16]}\right)$. 
To the best of the present authors' knowledge, no crystallographic data on the $\gamma_{1}$ phase of the binary Co-Zn system are available. It turned out that the selected area diffraction patterns (SAEDs) taken from the matrix phase (Figures 5(d) and (e)) can be readily indexed as $[2 \overline{1} \overline{1} 0]$ and $[1 \overline{2} 1 \overline{3}]$ directions in a hexagonal lattice with a set of data reported by Boström and Lidin ${ }^{[16]}$ for binary compound $\delta-\mathrm{Co}_{2} \mathrm{Zn}_{15}$. It is, however, important to realize that the $\delta$ phase is stable in the $\mathrm{Co}-\mathrm{Zn}$ binary system only between $675^{\circ} \mathrm{C}$ and $746{ }^{\circ} \mathrm{C}$ (Figure 3), which is significantly higher than the temperature used in the present investigation.

Even more unexpected was finding that SAEDs taken from the Co-Zn matrix phase within the periodic product microstructure with the composition corresponding to the binary $\gamma_{2}$-phase (i.e., at the location close to the $\mathrm{Zn}$ end-member) cannot be indexed using generally accepted information for the monoclinic $\gamma_{2}-\mathrm{CoZn}_{13}$ compound $(m C 28, C 2 / \mathrm{m}) .{ }^{[17,18]}$ Surprisingly, it can be done, as in the previous case, with the data for the same binary phase $\delta-\mathrm{Co}_{2} \mathrm{Zn}_{15}$.

In Figure 6, a montage of TEM (bright-field (BF)) images of the reaction zone developed in the annealed $\left(390{ }^{\circ} \mathrm{C}, 144\right.$ hours) $\mathrm{Co}_{2} \mathrm{Si} / \mathrm{Zn}$ diffusion couple at the location close to the $\mathrm{Zn}$ end-member, where composition of the matrix phase corresponds to the $\gamma_{2}$ phase of the Co-Zn system along with the SAEDs obtained from the particle in the band and from the matrix.

It should be mentioned that $\delta$ phase in the Co- Zn system is not a stoichiometric compound. It has a rather narrow homogeneity range and, as mentioned previously, is stable in the binary system within a temperature range of $675{ }^{\circ} \mathrm{C}$ to $746{ }^{\circ} \mathrm{C}$. The crystal structure for the $\delta$ phase was solved using single-crystal $\mathrm{X}$-ray and neutron powder diffraction data for the composition corresponding to the formula $\mathrm{Co}_{2} \mathrm{Zn}_{15} \cdot{ }^{[16]}$ According to the cited work, this is the first example of an intermetallic compound that crystallizes in the acentric hexagonal space group $P 6_{2} \quad(a=1.1292 \mathrm{~nm}$ and $c=0.7750 \mathrm{~nm})$. It has a unique chiral structure, which is composed of highly regular icosahedra of zinc sharing the vertices to form a double helix around the translation hexad. A chain of distorted Archimedean antiprisms is present inside these identical helices.

Obviously, results of the present study differ from what might be expected from the available information on the Co-Si-Zn phase diagram. At this point, it is important to stress that crystallographic studies on the (Co, Si, Zn) alloys involving Zn-rich intermetallics are
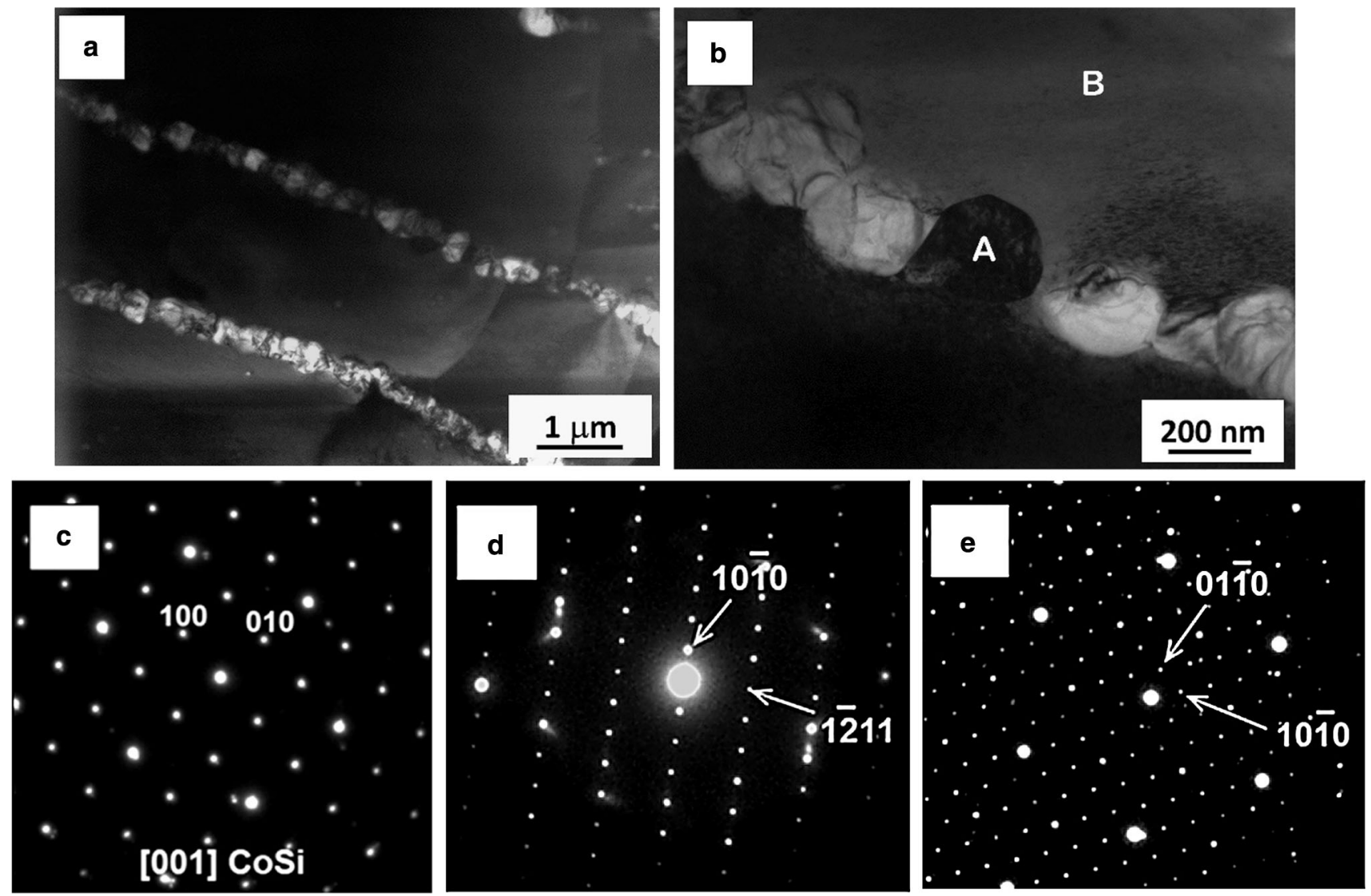

Fig. 6- $\mathrm{BF}$ TEM images of the reaction zone at the location close to the $\mathrm{Zn}$ end-member of the annealed $\left(390{ }^{\circ} \mathrm{C}, 144 \mathrm{~h}\right) \mathrm{Co} 2 \mathrm{Si} / \mathrm{Zn}$ diffusion couple: $(a)$ general view and $(b)$ magnified area showing the structure of the band together with SAEDs obtained from $(c)$ inclusion in the band (indicated by $\mathbf{A}$ in the $\mathrm{BF}$ image in (b)) and indexed as [001] direction in the cubic lattice of CoSi $\left(\mathrm{B} 20, c P 8, P 2_{1} 3\right.$, and $\left.a=0.4447 \mathrm{~nm}^{[15]}\right)$ and $(d)$ and (e) taken from the continuous matrix (indicated by $\mathbf{B}$ in the BF image in (b)) and indexed as [1216] and [0001] directions in a hexagonal lattice with the data for binary compound $\delta-\mathrm{Co}_{2} \mathrm{Zn}_{15}\left(P 6_{2}, a=1.1292 \mathrm{~nm}\right.$, and $\left.c=0.7750 \mathrm{~nm}^{[16]}\right)$. 
scarce. There have been only two attempts of phase identification in this system with X-ray diffraction (XRD) analysis using either powdered annealed (bulk) alloys ${ }^{[10]}$ or powder samples made by pulverization of the reaction products formed in diffusion couples between $\mathrm{Co}_{2} \mathrm{Si}$ and liquid $\mathrm{Zn} .^{[11]}$ Unfortunately, the reported results are not particularly convincing. Studying the original work and looking at the diffraction patterns presented in the cited articles, it is easy to conclude that the monoclinic $\gamma_{2}-\mathrm{CoZn}_{13}$ in the multiphase powder alloy samples has been identified by using only a very limited number of X-ray lines (often of rather low intensity). Given a severe overlapping of these lines with some of the X-ray lines corresponding to other alloy constituents, such phase identification becomes unwieldy at best and too intricate to be considered as a reliable procedure.

No explanation can be offered for the apparent ambiguities in the correlating results of the present electron microscopic and diffraction studies of the reaction zone in the annealed $\mathrm{Co}_{2} \mathrm{Si} / \mathrm{Zn}$ diffusion couples with the available crystallographic and phase diagram information. Nevertheless, it can be conjectured that a small amount of silicon, which was invariably detected (up to 0.7 at. pct) in the matrix phase of the reaction zone of the annealed $\mathrm{Co}_{2} \mathrm{Si} / \mathrm{Zn}$ diffusion couples, can stabilize the hexagonal structure of the $\delta$ phase and this intermetallic compound becomes stable in the ternary Co-Si-Zn system at $390{ }^{\circ} \mathrm{C}$.

As to the operational mechanism responsible for the pattering in the diffusion zone of the $\mathrm{Co}_{2} \mathrm{Si} / \mathrm{Zn}$ couples, it should be mentioned that, in general, the emergence of the periodic layered morphologies during solid-state reactions is still difficult to predict a priori. Nevertheless, based on the phase relations and knowledge of the relative diffusion mobilities of reactive species, several suggestions have been made. ${ }^{[1]}$

(1) A specific topology of a phase diagram allowing for the appearance of a two-phase reaction product (in our case, this is a hexagonal Co-Zn-based matrix phase (with the $\delta-\mathrm{Co}_{2} \mathrm{Zn}_{15}$ structure), containing up to 0.7 at. pct silicon and CoSi precipitates) in equilibrium with the binary end-member $\left(\mathrm{Co}_{2} \mathrm{Si}\right)$ of the diffusion couple is imperative to the periodic pattern formation. Individual inclusions of the CoSi product phase, embedded in a continuous Co-Zn-based intermetallic matrix, may be considered as inert markers formed in situ inside the reaction zone.

(2) Large differences in mobilities of species inside adjacent reaction product layers are required. The latter results in the divergence of the vacancy fluxes at (or in the vicinity of) the interphase interface. This is a prerequisite to the splitting of the bands of the inert inclusions. Indeed, from the location of the Kirkendall plane in the reaction zone of the annealed $\mathrm{Co}_{2} \mathrm{Si} / \mathrm{Zn}$ diffusion couple (Figure 1(a)), it was found that, at $390{ }^{\circ} \mathrm{C}, \mathrm{Zn}$ is by far the most mobile species in the Co-Zn-based matrix phase.
(3) The aggregation (clustering) of the CoSi particles (inclusions) into a band inside the reaction zone (Co- $\mathrm{Zn}$ intermetallic phase) is essential to the periodic pattern formation.

\section{CONCLUSIONS}

The periodic layered morphology generated in the reaction zone of the $\mathrm{Co}_{2} \mathrm{Si} / \mathrm{Zn}$ diffusion couples during annealing at $390{ }^{\circ} \mathrm{C}$ consists of bands of in situ-formed precipitates of cubic $\mathrm{CoSi}$, embedded in a continuous matrix of hexagonal Co-Zn-based phase containing up to 0.7 at. pet silicon. The band frequency (spacing) within the periodic microstructure is influenced by the crystallographic orientation of the grains in the $\mathrm{Co}_{2} \mathrm{Si}$ substrate. The formation of the hexagonal intermetallic of the same crystal structure as the binary $\delta$ phase of the $\mathrm{Co}-\mathrm{Zn}$ system can be attributed to the possible stabilizing effect of silicon: the $\delta$ phase becomes stable in the ternary $\mathrm{Co}-\mathrm{Si}-\mathrm{Zn}$ system at $390{ }^{\circ} \mathrm{C}$.

Although the appearance of loops decorated by $\mathrm{CoSi}$ inclusions embedded in the Co-Zn-based intermetallic matrix, observed in a section of the periodic layered reaction zone of the $\mathrm{Co}_{2} \mathrm{Si} / \mathrm{Zn}$ couple perpendicular to the diffusion direction, does not lend itself at this point to a straightforward analysis, some conjectures can still be made. Most likely this conspicuous phenomenon can be linked to the extraordinary crystal structure of the product matrix phase, related to the binary hexagonal compound $\delta-\mathrm{Co}_{2} \mathrm{Zn}_{15}$, and the expected anisotropy of diffusion behavior in this intermetallic phase.

\section{ACKNOWLEDGMENT}

The research was financed by the National Science Centre, Poland, under Project No. 2014/15/B/ST8/ 00195.

\section{OPEN ACCESS}

This article is licensed under a Creative Commons Attribution 4.0 International License, which permits use, sharing, adaptation, distribution and reproduction in any medium or format, as long as you give appropriate credit to the original author(s) and the source, provide a link to the Creative Commons licence, and indicate if changes were made. The images or other third party material in this article are included in the article's Creative Commons licence, unless indicated otherwise in a credit line to the material. If material is not included in the article's Creative Commons licence and your intended use is not permitted by statutory regulation or exceeds the permitted use, you will need to obtain permission directly from the copyright holder. To view a copy of this licence, visit http://creat ivecommons.org/licenses/by/4.0/. 


\section{REFERENCES}

1. A. Kodentsov, J. Wojewoda-Budka, and A. Wierzbicka-Miernik: in Diffusion Controlled Growth and Oxidation of Metal-Silicides, Diffusion Foundations, A. Paul, ed., Trans Tech Publications Ltd., Aedermannsdorf, Switzerland, 2019, vol. 21, pp. 157-89.

2. M.R. Rijnders and F.J.J. van Loo: Scripta Metall. Mater., 1995, vol. 32, pp. 1931-35.

3. C. Yongchong, Q. Lu, Z. Yonggang, and C. Changqi: Acta Metall. Sinica, 2005, vol. 41, pp. 235-41.

4. J. Bardeen and C. Herring: in Imperfections in Nearly Perfect Crystals, W. Shockley, J.H. Hollomon, R. Maurer, and F. Seitz, eds., Wiley, New York, NY, 1952, pp. 261-88.

5. A.N. Zaikin and A.M. Zhabotinsky: Nature, 1970, vol. 225, pp. 535-37.

6. K. Osinski: Ph.D. Thesis, Eindhoven, The Netherlands, 1983.

7. A.A. Kodentsov, M.R. Rijnders, and F.J.J. van Loo: Acta Mater., 1998, vol. 46, pp. 6521-28.

8. A.A. Kodentsov, M.J.H. van Dal, C. Cserháti, A.M. Gusak, and F.J.J. van Loo: Def. Diffus. Forum, 2001, vols. 194-199, pp. 1491-1502.

9. T.B. Massalski: Binary Alloy Phase Diagrams, ASM, Metal Park, $\mathrm{OH}, 1986$.
10. W. Wang, F. You, M. Zhao, Z. Li, and Y. Wu: Metall. Mater. Trans. A, 2014, vol. 45A, pp. 4175-80.

11. Y. Liu, M. Tang, Z. Dong, C. Wu, and X. Su: Surf. Coat. Technol., 2016, vol. 307, pp. 892-97.

12. O.V. Duchenko and V.I. Dybkov: J. Mater. Sci. Lett., 1999, vol. 18, pp. 1311-13.

13. O.V. Duchenko, V.M. Vereshchaka, and V.I. Dybkov: J. Alloys Compd., 1999, vol. 288, pp. 164-69.

14. Y. Takamatsu, O. Minho, and M. Kajihara: Mater. Trans., 2017, vol. 58 (4), pp. 567-73.

15. K. Ishida, T. Nishizawa, and M.E. Schlesinger: J. Phase Equilib., 1991, vol. 12, pp. 587-96.

16. M. Boström and S. Lidin: J. Solid State Chem., 2002, vol. 166, pp. 53-57.

17. W.B. Pearson: The Crystal Chemistry and Physics of Metals and Alloys, Wiley, New York, NY, 1972.

18. JCPDS File Nos. 65-1237 and 29-0523, International Center for Diffraction Data, Newtown Square, PA, PCPDFWIN v. 2.02, 1999.

Publisher's Note Springer Nature remains neutral with regard to jurisdictional claims in published maps and institutional affiliations. 